ARTIGOS

\title{
Processos de construção da autonomia docente: Análise do planejamento de uma abordagem temática com professores de Ciências da Educação Básica
}

D’Andréa do Rosário Nogueira João Ricardo Neves da Silva

\begin{abstract}
RESUMO:
Este artigo trata da descrição do processo de construção conjunta de conhecimentos conceituais e do desenvolvimento de características de autonomia docente por professores participantes de um Pequeno Grupo de Pesquisa (PGP) na escola. Para analisar os diálogos obtidos por meio de gravação em áudio de encontros desse grupo, nos pautamos principalmente nos referenciais sobre a autonomia docente em grupos de professores, além de trabalhos da linha de formação de professores de ciências. Essas análises foram realizadas por agrupamentos de categorias e sistematizam os conteúdos conceituais e os elementos da autonomia docente desenvolvidos, em conjunto pelos professores, no processo de planejamento conjunto. Foi possível identificar momentos nos quais os professores vão compreendendo os elementos teóricos da questão-tema debatida, e ainda situações nas quais se pode afirmar a constituição de elementos iniciais de autonomia docente. Assim, apontamos para o potencial da formação de grupos de pesquisa por professores na escola na elaboração de conhecimentos conceituais e na construção da autonomia dos docentes.
\end{abstract}

\section{PALAVRAS-CHAVE:}

Autonomia Docente, Pequeno Grupo de Pesquisa, Formação de Professores de Ciências,

\begin{abstract}
:
This article presents the description of the process of joint construction of conceptual knowledge and the development of characteristics of teacher autonomy by teachers participating in a Small Research Group (PGP) at the school. In order to analyze the dialogues obtained through audio recording of meetings of this group, we focus mainly on the references about the teachers autonomy in groups of teachers, and references about science teachers education. These analyzes were made by groupings of categories and its systematized the conceptual contents and the elements of the teaching autonomy developed, jointly by the teachers, in the joint planning process. It was possible to identify moments in which teachers understand the theoretical elements of the theme-issue that was in debated, and still situations in which the constitution of initial elements of teacher autonomy can be affirmed. Thus, we point to the potential of the formation of research groups by teachers in the school in the elaboration of conceptual knowledge and in the construction of the autonomy of the teachers.
\end{abstract}

\section{KEYWORDS:}

Teachers autonomy, Small research group, Science teachers education 


\section{autêntica}

\section{INTRODUÇÃO: FORMAÇÃO CONTINUADA DE PROFESSORES DE CIÊNCIAS NO CONTEXTO DA RA- CIONALIDADE TÉCNICA: INTRODUÇÃO À QUESTÃO DE PESQUISA}

Ao tratarmos da formação de professores de ciências, tanto no âmbito inicial quanto continuado, nos deparamos com uma série de possibilidades teóricas e práticas oriundas de diferentes vertentes. Desde a investigação dos conhecimentos produzidos pelos professores em formação continuada (TERNEIRO-VIEIRA, 2002), ou dos saberes docentes dos professores de ciências (SABINO e PIETROCOLA, 2016; CAMPOS e DINIZ, 2016; CARVALHO, 1993), sistematizar as características necessárias aos professores dessas disciplinas têm sido um trabalho de pesquisa bastante desenvolvido pela comunidade científica da área de ensino.

Desde meados da década de 2000, o processo de construção da autonomia docente também tem composto o cenário de investigações dentro dessa perspectiva, principalmente após a sistematização dos elementos dessa autonomia em uma perspectiva crítica por Contreras (2002). É nesse conjunto de discussões teóricas que se posiciona esta pesquisa, na medida em que investiga o caminho de um grupo de professores no que diz respeito ao desenvolvimento de características de autonomia docente e da construção conjunta de conhecimentos de conteúdo.

O estudo das produções ocorridas em um grupo de pesquisa de professores se dá no contexto teórico da necessidade de um processo formativo de professores de ciências que busque superar os imperativos da chamada racionalidade técnica que vêm fundamentando tanto a formação quanto a atuação profissional dos docentes da escola. Nesse sentido, partimos do pressuposto segundo o qual a função do professor da educação básica está dominada por imperativos sistêmicos que interferem nas possibilidades criadoras, críticas, ou, em outras palavras, emancipatórias necessárias no trabalho docente. Esta situação é expressa também por Contreras (2002) quando argumenta que:

\footnotetext{
As escolas ou outras formas de organização local para a educação, não podem definir por si mesmas seus âmbitos de atuação ou suas formas de relação social, senão que devem ater-se à composição e funções designadas e aos tipos de participação já estabelecidos. O conselho escolar e a direção, por exemplo, são organismos já definidos, cuja composição e competência são fixadas por lei, não pelos próprios organismos. E, ao definirem-se tais organismos, fica excluída a possibilidade de criação de qualquer outra forma de experimentar a constituição do encontro entre professores e sociedade. (CONTRERAS, 2002, p. 65).
}

As escolas apresentam em sua organização, uma hierarquia, na qual aos professores compete executar as ações e deliberações de outros agentes da educação. Podemos identificar isso nas escolas públicas, nas quais o estado implementa políticas educacionais que pouco contemplam o processo criador dos professores. Nos argumentos de Lopes $(2013$, p.6), "Diante disso, a escola muitas vezes torna-se uma das vias da pseudodemocratização do conhecimento, o que contribui para a crise educacional vigente".

Diversos autores, tais como Bastos e Nardi (2009), AUTOR (ANO), Lopes (2013) e Martinez (2010), ajudaram a compor a análise mais aprofundada dos modelos de formação de professores de ciências, analisando seus perfis de atuação e fundamentação teórica. Essa compreensão nos mostra traços de uma fundamentação tecnicista desde a sua formação inicial, que busca um professor técnico, com habilidades para transmitir, em sala de aula, o conhecimento obtido em sua graduação.

A ideologia tecnicista do currículo tradicional reduz o ensino à transmissão de conteúdos disciplinares que são abordados de maneira desinteressada e investidos de uma aparente neutralidade política, de modo que os professores terminam reproduzindo essa ideologia, focando o ensino na 


\section{autêntica}

transmissão desses conteúdos, e dessa forma deixam em um segundo plano as questões do por que, para que e para quem ensinar Ciências. (MARTINEZ, 2010, p.140).

O excesso de burocracia a que os professores são submetidos todos os dias geram uma intensificação em seu trabalho, levando-os á uma rotina desgastante, que impede o seu refletir, sendo levados pela ação do tempo a se isolar dos colegas, privando-os de tempo para encontros em que se discutem e se trocam experiências profissionais, fomentando-se o individualismo, reduzindo seu trabalho á diária sobrevivência de dar conta das tarefas que são obrigados a cumprir. Além disso, a grande maioria de docentes no Brasil necessita trabalhar em várias escolas, para assegurar o seu sustento e assim, não tem tempo para questionar ordens ou encaminhamentos vindos de uma gestão verticalizada ou mesmo refletir sobre sua prática.

Uma vez que se aponta para um cenário no qual os aspectos criativos e intelectuais dos professores precisa ser colocado em pauta, que caminhos a pesquisa nessa área pode contribuir na elucidação de elementos possíveis, referenciais teóricos e ações práticas devem ser estudadas nessa direção?

Imbuídos por essa perspectiva de propor e estudar processos formativos de professores de ciências que buscassem desenvolver posturas e momentos críticos junto a esses, alguns pesquisadores investiram na construção de grupos com os docentes da educação básica, na escola e, a partir desses grupos, sistematizaram uma série de características decorrentes desses PGP na escola.

Santos (2013) e Lopes (2013) discorrem sobre as possibilidades formativas dos grupos de professores. Esta argumenta que:

A profissionalização docente deva ser imersa em esferas de debate que incluam, primordialmente, os agentes mais diretos. Neste caso, os agentes envolvidos são os próprios professores, que são "capazes de avaliar em plena consciência, o trabalho de seus pares" (idem, p. 6). Estes agentes vivenciam e compartilham problemas, possibilidades, experiências, entre outros elementos que compõem o mundo subjetivo, objetivo e social. (LOPES, 2013, p. 66)

Na visão da autora, aspectos da profissionalidade docente são expressos e formados no ambiente de debate sobre práticas e ações que incluam os sujeitos diretos da ação. Ainda expõe que tais espaços se constituem na condição de esferas públicas, quando diz que: "deve ser garantido um espaço onde os professores possam refletir e reformular suas concepções sobre ensino, bem como expor estas concepções diante de um público interessado que as debata e reformule uma posição diante da esfera pública educacional." (LOPES, 2013, p. 69).

AUTOR (ANO) estuda as produções dos professores de uma escola pública que se reuniram em um PGP e constata o desenvolvimento de posturas de parceria entre docentes da universidade e da escola quando em um trabalho conjunto de ensino de ciências e matemática.

Sob este enfoque, a primeira característica do Projeto que fica ressaltada é a exposição dos participantes, tanto aqueles da universidade como da escola, em principio "conformados" à perspectiva disciplinar, a um longo tempo de convívio comum, durante as ocasiões de apresentação de trabalho e discussão de problemas. A escola básica, então, se levanta como um espaço, na sociedade, em que as resistências para aproximação, das diferentes áreas da cultura, não são intransponíveis. Nesse sentido, "a fraqueza" da escola, aquela relacionada ao nível sempre introdutório de abordagem dos conteúdos, torna-se o seu "ponto forte" e, neste primeiro sentido, a universidade precisa da escola. (p. 122) 


\section{autêntica}

Além disso, trabalhos como os de Tenreiro-Vieira (2002), ao analisarem as produções de conhecimentos teóricos por professores em grupo de estudos, mostram, por exemplo, que "foi visível uma mudança na operacionalização de estratégias/atividades como o debate/discussão e o questionamento" (p. 202), e que "em vez de uma orientação quase exclusiva na aquisição de conhecimentos científicos, passaram a contemplar o explicitar das inter-relações da Ciência e da Sociedade e, por vezes, com a Tecnologia, e a apelar para as capacidades de pensamento." (p. 202).

Ou seja, há na literatura uma série de descrições que fundamentam a ideia de que as produções ocasionadas nos grupos de professores podem ser tanto de natureza prático-pedagógica quanto de conteúdos específicos. Assim, diante dessas argumentações, do cenário de pouca valorização da formação crítica de professores de ciências no âmbito oficial e das possibilidades apontadas pelos estudos dos grupos de professores, é que decidimos construir e estudar um aspecto de PGP na escola.

A perda da autonomia docente na realização de sua prática acontece á medida que este assume como inevitável sua dependência com respeito ás decisões externas em relação ao reconhecimento de autoridades legítimas que exercem o controle burocrático e hierárquico (APPLE, 1987, p.153171). Ao renunciar a sua autonomia como docente, aceita a perda do controle do seu trabalho e a supervisão externa sobre o mesmo." (CONTRERAS, 2002, p. 38).

Com esses argumentos, a pergunta principal que se pretende abordar com esta investigação é descrita da seguinte maneira: Quais são os elementos de construção da autonomia docente presentes nas interações entre professores da Educação Básica quando em situação de planejamento conjunto da abordagem de uma questão temática na escola? Nesse sentido, esta pesquisa tem como objetivo geral identificar e analisar o processo de construção da autonomia docente e de conhecimentos conceituais em um Pequeno Grupo de Pesquisa (PGP) de professores da educação básica, tendo como objetivos específicos:

- Analisar as interações linguísticas entre os professores de um PGP com o objetivo de identificar se e como se desenvolvem características de autonomia docente.

- Identificar e sistematizar os conhecimentos produzidos e debatidos nesse PGP, com respeito à prática docente e ao conteúdo curricular pertinente ao projeto temático em debate.

Para este fim, nos apoiamos nos referenciais teóricos que versam sobre o desenvolvimento da autonomia docente, assim como os construtos teóricos sobre interações linguísticas e construção de conhecimentos em grupos de professores, ambos a partir das perspectivas críticas.

\section{FUNDAMENTOS TEÓRICOS: AUTONOMIA DOCENTE E GRUPOS DE PROFESSORES DE CIÊNCIAS}

Nessa pesquisa, dois elementos teóricos foram considerados primordiais de serem compreendidos na intenção de sistematizar as construções conjuntas de conhecimentos realizadas pelos professores em um PGP. São eles: o processo de construção da autonomia docente em grupos de professores (CONTRERAS, 2002; AUTOR, ANO); e o processo de construção de conhecimentos por professores em grupos, sejam esses denominados grupos colaborativos (FIORENTINI, 2012; PIMENTA, GARRIDO e MOURA 2001) ou comunidades de aprendizagem (KEMMIS, 1993, CORZO, QUINTANA e YUCOSA, 2008). Assim, a perspectiva principal de trabalho que fundamenta a pesquisa aqui apresentada é aquela que defende a formação de grupos de estudo e pesquisa como parte integrante e fundamental do processo formativo de professores de ciências.

Partimos da reflexão de que a instrumentalização do trabalho docente por parte de um currículo tecnicista foi alvo de críticas desenvolvidas por vários autores, tais como GIROUX (2003), CONTRERAS (2002), além 


\section{autêntica}

de vários pesquisadores leitores desses referenciais. Algumas dessas críticas questionam a aparente neutralidade dos conteúdos curriculares e da função docente, ocultando os interesses e as normatizações em seu correspondente estabelecimento. Martinez (2010) resume as principais críticas relativas à perspectiva tecnicista de trabalho docente.

A ideologia tecnicista do currículo tradicional reduz o ensino á transmissão de conteúdos disciplinares que são abordados de forma desinteressada e investidos de uma aparente neutralidade política, de modo que os professores terminam reproduzindo essa ideologia focando o ensino na transmissão desses conteúdos, e dessa forma deixam em um segundo plano as questões do por que, para que e para há quem ensinar Ciências. (MARTINÉZ, 2010, p.140).

Assim, há de se considerar o cenário de crítica aos aspectos técnicos e burocráticos da formação e da atuação docente e de defesa de posturas formativas que tragam à atuação docente papel intelectual, criador e autônomo. Ou seja, corpo de referenciais teóricos que fundamentam esse trabalho são aqueles que se posicionam nas perspectivas críticas de formação docente.

Contreras (2002), como referencial principal desta pesquisa, traz contribuição primordial na definição tanto do diagnóstico de crise da profissionalidade docente, descrito anteriormente, como na elaboração de um conceito de autonomia docente construído a partir de uma perspectiva crítica de formação de professores. O autor percebe a importância de processos coletivos autônomos nas escolas, como ambientes propícios ao desenvolvimento de uma reflexão crítica da prática docente e como um mecanismo de ruptura com a burocratização e o controle administrativo.

Por conseguinte, a introdução de processos coletivos de trabalho nas escolas pode se transformar em um fator desencadeante da reflexão crítica, da mesma maneira que a burocratização e o controle administrativo em que se define esta tarefa pode ser o fator chave na limitação do desenvolvimento crítico da análise de nossa prática. (CONTRERAS, 2002, p. 267).

Contreras (2002) entende ainda que a autonomia é um processo coletivo, construído em um espaço coletivo de interação, no qual a autonomia docente é vista juntamente com a autonomia social. E é nesta visão, que entendemos o processo de autonomia docente, no qual o professor não está sozinho e cuja verdadeira autonomia só acontece de fato, no contato com o outro, na coletividade das ideias e dos fazeres.

Mas, o que temos visto nas escolas, desde a década de 1990 até os dias de hoje é o surgimento de reformas educacionais, tendo como elementos essenciais: o currículo, as escolas e os professores. O currículo que norteia o trabalho docente, deve se pautar pela realidade do espaço onde está sendo adaptado pelos docentes. Conforme Contreras (2002, p. 233)

Embora se pretendesse um currículo igual para toda a população, as diferenças sociais e culturais de cada contexto, a composição concreta de alunos de cada escola, os recursos materiais e culturais disponíveis no meio e para os alunos e professores, fazem, com que, na prática, se tenha que pensar que o currículo é sempre a mediação e recriação de uma proposta em função de todas essas imposições. (CONTRERAS, 2002, p. 233)

Nesta questão, o docente pode e deve adaptar o currículo oficial a sua realidade local, se apropriando do mesmo. Essa também é uma das facetas da autonomia que acarreta ainda mais trabalho ao professor, pois sempre haverá a necessidade de interpretar e adequar o currículo ao contexto, mas que demonstra um encaminhamento para a atuação do professor com propriedade sobre seu conteúdo de ensino. 
Nessa perspectiva, o autor vê na união e no encontro de ideias e de fazeres, dentro de um processo dialógico, pautado no respeito e na reflexão, parte importante do processo de construção da autonomia docente.

Como afirma Contreras (2002), "a autonomia do professor em sala de aula, com qualidade deliberativa da relação educativa, se constrói na dialética entre as convicções pedagógicas e as possibilidades de realizá-las, de transformá-las nos eixos reais do transcurso e da relação de ensino" (p.198). É nesse contexto que, "tanto a autonomia profissional como pessoal não se desenvolvem, nem são definidas pela capacidade de isolamento, pela capacidade de "se arranjar sozinho", nem pela capacidade de evitar influências ou as relações" (idem, p.199). Pelo contrário, a autonomia, vista sob a perspectiva da nova teoria crítica, tem na intersubjetividade o meio para a formação social e para a emancipação.

O autor ainda descreve o potencial da teoria crítica para a educação, de forma a suscitar as possibilidades de entendimento de suas deformações ideológicas e de ação pelos grupos. Em sua visão, a autonomia docente não pode estar desvinculada da tentativa de construir determinados contextos, valores e práticas de cooperação, no qual a dialética tem papel determinante na transformação das relações de ensino. (CONTRERAS, 2002).

Grupos de estudos podem desenvolver efeitos bastante interessantes e bem mais significativos que a simples participação passiva, na função de ouvintes e receptores do conhecimento, em cursos de formação, ou "capacitação" de professores oferecidos vez ou outra pelos estados.

\begin{abstract}
Uma perspectiva de relação e construção da autonomia a define não como a posse de direitos e atributos, mas como a busca e construção de um encontro pedagógico em que as convicções e as pretensões abrem um espaço de entendimento no qual podem se desenvolver por meio do diálogo, tanto em sua significação como em sua realização. Portanto, a autonomia tanto faz referência a uma disposição de encontro pedagógico, como á qualidade e á consequência deste. (CONTRERAS, 2002, p.200).
\end{abstract}

Nesse sentido, a possibilidade de repensar a formação de professores se inicia com a formação do PGP, "que vivendo a realidade da escola, tem agora a possibilidade da comunicação e da interação, em uma esfera de debate, onde compartilham problemas, dificuldades, possibilidades, experiências" (LOPES, 2013, p. 66). Dentro desta concepção, a noção de autonomia docente é entendida pelo professor como integrante de deliberações no campo educacional, bem como em sua prática cotidiana em sala de aula e de interação entre os pares.

A partir das reflexões apresentadas até então neste capítulo, entendemos os aspectos da proletarização e principalmente da tecnização do trabalho docente. Nesse contexto, entendemos que a formação de PGP nas escolas se constitui como uma forma de abarcar elementos que vão ao encontro das características descritas aqui, revelando aspectos da formação de professores pautadas na necessidade de superação da dita tecnização. É nesse sentido, da busca por situações formativas que desenvolvam junto aos professores da escola, possibilidades de formação no sentido crítico desta palavra, que envolvemos este trabalho na busca desses aspectos.

\title{
METODOLOGIA: A CONSTITUIÇÃO DE UM PEQUENO GRUPO DE PESQUISA NA ESCOLA E DOS DADOS DA PESQUISA.
}

A pesquisa se desenvolveu no âmbito da análise do processo de constituição e manutenção de um PGP entre professores de uma escola pública com o objetivo de planejarem em conjunto ações de um projeto sobre o 


\section{autêntica}

consumo racional de lixo plástico. Nesse sentido, o que relatamos aqui trata exatamente da descrição desse processo de formação do PGP e os encaminhamentos dos encontros.

No nosso caso, as reuniões do PGP aconteceram na escola, local de pertencimento de todos. A pesquisa teve início com a inserção da pesquisadora no campo, que é uma escola estadual do interior do estado de Minas Gerais. Tal escola foi escolhida, pois a pesquisadora além de ser professora na mesma por vários anos, também esteve à frente da mesma, como diretora, por cinco anos Isso se mostrou relevante na escolha da escola, pois facilitaria a adesão do projeto pelos docentes e como a pesquisadora conhece o ambiente, através da pesquisa, poderia agregar mais valores ao ensino ministrado ali.

Após negociações com a direção e com os professores, foi acordado que o PGP se reuniria na escola, quinzenalmente, às quartas-feiras. É importante destacar que o grupo formado teve como função inicial o planejamento de atividades para execução de um projeto piloto e a pesquisadora, que também é professora, busca identificar características de autonomia docente nesse grupo, a partir das discussões e pesquisas envolvendo a questão tema. O quadro 1 traz as descrições dos professores que toparam compor o PGP, descritos com nomes fictícios escolhidos pelos próprios.

\section{QUADRO 1: CARACTERIZAÇÃO DOS INTEGRANTES DO PGP.}

\begin{tabular}{|c|c|}
\hline Professor (a) & Caracterização \\
\hline Professor Luis & $\begin{array}{l}\text { É formado em licenciatura em História. Leciona esta disciplina nos anos } \\
\text { finais do Ensino Fundamental, na Escola Estadual "Professor Souza Nilo" } \\
\text { desde 2012, após ser aprovado em concurso público estadual. }\end{array}$ \\
\hline Professor Maria & $\begin{array}{c}\text { É formada em Ciências Biológicas e leciona Biologia, no Ensino Médio e } \\
\text { Ciências, nos anos finais do E. Fundamental, também na E.E."Professor } \\
\text { Souza Nilo", desde 2011, quando foi designada para substituir a pesquisadora } \\
\text { que assumiu a gestão escolar. }\end{array}$ \\
\hline Professora Ana & $\begin{array}{l}\text { Também é licenciada em Ciências Biológicas e leciona Biologia e ciências, } \\
\text { aos alunos do ensino regular e também da EJA. Faz parte do corpo docente } \\
\text { da escola desde } 2007 .\end{array}$ \\
\hline Professor João & $\begin{array}{c}\text { É formado em Licenciatura em Química. É o mais novo docente da escola, } \\
\text { pois assumiu as aulas no ano de } 2015 \text {, ao ser designado para substituir a } \\
\text { professora titular. }\end{array}$ \\
\hline Professora Camila & $\begin{array}{c}\text { É formada em Pedagogia e está exercendo sua função na biblioteca da es- } \\
\text { cola, auxiliando os alunos, nos trabalhos e pesquisas indicados pelos demais } \\
\text { professores. Está na E.E."Professor Souza Nilo", desde } 2012\end{array}$ \\
\hline
\end{tabular}

Fonte: Elaborado pelos autores

Os dados obtidos na pesquisa são fruto da análise de cinco reuniões do PGP. Essas reuniões foram gravadas após aprovação de todos e transcritas posteriormente. Direcionamos nossas análises para os episódios selecionados a partir das transcrições das falas dos integrantes do PGP e buscamos identificar neles características de autonomia docente e também elementos oriundos do trabalho em grupo e do tratamento da questão tema: "Produção e consumo de lixo plástico", tendo como sub-tema: "O lixo eletrônico". 
De acordo com os nossos referenciais teóricos e metodológicos, foram selecionadas nas análises as interações entre os membros do PGP. Dentro do contexto no dispositivo de análise, não tratamos as falas como referência de interpretações, pois estas são características do sujeito isolado, e em nosso caso, nos interessa a comunicação construída na coletividade de ideias, a partir do que foi entendido pela pesquisadora como fruto da interação conjunta, a partir de um tema.

O procedimento de análise foi realizado seguindo as etapas descritas a seguir:

1) Seleção dos episódios de análise: A primeira etapa da análise consiste na seleção dos episódios de análise a partir das transcrições das reuniões. Caracterizamos como episódio a ser analisado um conjunto completo de elementos de fala que contemplam um determinado tema. Sendo assim, um episódio pode se constituir por um conjunto de falas de grande extensão ou ainda, de pequena extensão, desde que contemple uma temática específica sobre a qual os participantes argumentam.

2) Caracterização dos conteúdos das falas: Em cada episódio de análise buscamos identificar e caracterizar os conteúdos das falas com respeito aos elementos objetivados na pesquisa (características de autonomia e conhecimentos conceituais sobre a questão tema). São exemplos de caracterização "valorização da opinião do grupo,", "compreensão do aspecto social da questão-tema", "organização conjunta de ações do projeto".

3) Sintetização dos conteúdos das falas: Diante das falas apresentadas pelos membros do Grupo e das suas caracterizações, empreendemos uma síntese da fala e da característica, visando a construção gradual dos elementos de autonomia docente e de conteúdo pretensos.

Nesta fase também criamos alguns eixos temáticos de análise, para facilitar o agrupamento das falas e das ações realizadas pelo PGP. Assim, no quadro 2 é exposto um exemplo do quadro analítico, destacando os excertos de fala, a caracterização e a sintetização.

\section{QUADRO 2: EXEMPLO DE QUADRO ANALÍTICO DOS DADOS.}

\begin{tabular}{|c|c|c|}
\hline \multicolumn{2}{|c|}{ R1E1: A importância da educação. } \\
\hline Excerto & $\begin{array}{c}\text { Caracterização } \\
\text { das falas }\end{array}$ & Sintetização \\
\hline $\begin{array}{c}\text { Pesquisadora: Então agora, a gente } \\
\text { vai recapitular o que a gente viu na } \\
\text { semana passada. Primeiramente, nós } \\
\text { vimos à necessidade e importância de } \\
\text { desenvolvermos o projeto. Na reunião } \\
\text { passada, foram apresentadas várias } \\
\text { idéias sobre o tema e todas muito } \\
\text { boas e a gente viu também que como } \\
\text { envolve conscientização o retorno será } \\
\text { á médio }\end{array}$ & $\begin{array}{c}\text { Manutenção cons- } \\
\text { tante do tema em } \\
\text { estudo longo prazo. }\end{array}$ & $\begin{array}{c}\text { A pesquisadora inicia a conversa } \\
\text { lembrando a todos quais foram } \\
\text { as decisões tomadas pelo } \\
\text { grupo no encontro anterior. } \\
\text { Característica importante na } \\
\text { compreensão conjunta do tema. }\end{array}$ \\
\hline
\end{tabular}




\begin{tabular}{|c|c|c|}
\hline $\begin{array}{l}\text { Pesquisadora: Porque a gente sabe, que } \\
\text { se tratando de conscientização tudo é } \\
\text { muito demorado. Vocês deram a ideia } \\
\text { da gente fazer um projeto piloto ainda } \\
\text { este ano, com uma turma que será } \\
\text { escolhida pelo grupo. Vocês deram ideia } \\
\text { ainda de uma gincana entre as turmas e } \\
\text { que aquela que conseguisse recolher o } \\
\text { maior número de resíduo plástico fosse } \\
\text { a vencedora e que realizássemos uma } \\
\text { viagem com a mesma. }\end{array}$ & $\begin{array}{c}\text { Manutenção } \\
\text { constante do tema } \\
\text { em estudo. } \\
\text { Exemplos com } \\
\text { elementos da própria } \\
\text { prática }\end{array}$ & $\begin{array}{l}\text { A pesquisadora se mantém } \\
\text { reafirmando as ideias } \\
\text { apresentadas pelo grupo para } \\
\text { discussão e apresenta uma visão } \\
\text { pessoal sobre o processo de } \\
\text { conscientização. A ideia de que } \\
\text { este processo é demorado. }\end{array}$ \\
\hline
\end{tabular}

Fonte: Elaborado pelos autores

Dessa maneira, sob as recomendações desses referenciais e com esses procedimentos analíticos, passamos a identificar os episódios de análise e buscar os elementos possibilitados pela construção conjunta de um projeto por professores da educação básica.

\section{DA CONSTRUÇÃO CONJUNTA DE CONHECIMENTOS SOBRE A QUESTÃO-TEMA E A POSSIBILIDADE DE DESENVOLVIMENTO DE CARACTERÍSTICAS DE AUTONOMIA: ANÁLISE E COMPREENSÃO DOS DADOS}

Ao apresentarmos os dados e as compreensões teóricas desses, destacamos que serão demonstrados aqui trechos representativos da análise, uma vez que o corpus de materiais analisados foi bastante extenso. Nesse sentido, a apresentação dos dados se dá por reunião do PGP e pretende demonstrar o processo de construção conjunta de conhecimentos conceituais e características de autonomia ao longo do andamento dos encontros do grupo.

A primeira reunião do PGP, como um momento inicial de encontro entre os docentes, visa primordialmente a discussão de motivações e pretensões para a participação nesse tipo de grupo. Identificamos, nesse momento, principalmente relatos da própria prática e concepções pessoais dos professores a respeito da questão tema, como é possível observar no Quadro 3 e em sua análise. 


\section{QUADRO 3: QUADRO ANALÍTICO DO EPISÓDIO E2 DA PRIMEIRA REUNIÃO DO PGP.}

\begin{tabular}{|c|c|c|}
\hline \multicolumn{3}{|c|}{ R1E2: A importância do desenvolvimento da questão tema! } \\
\hline Excerto & Caracterização & Síntese \\
\hline $\begin{array}{l}\text { Pesquisadora: Então agora, a gente vai } \\
\text { recapitular o que a gente conversou na } \\
\text { semana passada, quando eu fiz o convite. } \\
\text { Primeiramente, nós vimos à necessidade } \\
\text { e importância de desenvolvermos o } \\
\text { projeto. Naquele momento, foram } \\
\text { apresentadas várias ideias sobre o tema } \\
\text { e todas muito boas e a gente viu também } \\
\text { que como envolve conscientização o } \\
\text { retorno será á médio e longo prazo. }\end{array}$ & $\begin{array}{l}\text { Manutenção constante do tema } \\
\text { em estudo. } \\
\text { Apresentação das ideias dos } \\
\text { colegas para apreciação do } \\
\text { grupo }\end{array}$ & $\begin{array}{c}\text { A pesquisadora inicia a } \\
\text { conversa lembrando a } \\
\text { todos quais foram as ideias } \\
\text { apresentadas pelo grupo em } \\
\text { momento anterior. }\end{array}$ \\
\hline $\begin{array}{l}\text { Pesquisadora: Porque a gente sabe, que } \\
\text { se tratando de conscientização tudo é } \\
\text { muito demorado. Vocês deram a ideia } \\
\text { da gente fazer um projeto piloto ainda } \\
\text { este ano, com uma turma que será } \\
\text { escolhida pelo grupo. Vocês deram ideia } \\
\text { ainda de uma gincana entre as turmas e } \\
\text { que aquela que conseguisse recolher o } \\
\text { maior número de resíduo plástico fosse } \\
\text { a vencedora e que realizássemos uma } \\
\text { viagem com a mesma. }\end{array}$ & $\begin{array}{l}\text { Manutenção constante do tema } \\
\text { em estudo. } \\
\text { Propostas de ação sobre o } \\
\text { projeto }\end{array}$ & $\begin{array}{l}\text { A pesquisadora se mantém } \\
\text { reafirmando as ideias } \\
\text { apresentadas pelo grupo } \\
\text { para discussão e apresenta } \\
\text { uma visão pessoal sobre o } \\
\text { processo de conscientização. }\end{array}$ \\
\hline $\begin{array}{c}\text { Pesquisadora: Dá pra gente perceber, que } \\
\text { somos nós que levamos nossos filhos á } \\
\text { se tornarem consumidores desmedidos. } \\
\text { Como nosso público alvo são os alunos, } \\
\text { temos que pensar neles neste primeiro } \\
\text { momento. Depois que eles apreenderem, } \\
\text { com certeza, fará a diferença em suas } \\
\text { casas. }\end{array}$ & $\begin{array}{l}\text { Exemplo do cotidiano sobre a } \\
\text { questão-tema }\end{array}$ & $\begin{array}{l}\text { A pesquisadora se posiciona } \\
\text { tentando identificar } \\
\text { previamente uma dificuldade }\end{array}$ \\
\hline $\begin{array}{l}\text { Pesquisadora: Só que a gente não } \\
\text { precisa ter a pretensão de achar que em } \\
\text { uma sala, todos os alunos agirão com } \\
\text { consciência. Numa sala com trinta, trinta } \\
\text { e cinco, se a gente conseguir dez ou até } \\
\text { cinco, já está bom, né? }\end{array}$ & $\begin{array}{l}\text { Reflexão sobre o projeto a partir } \\
\text { de elementos da própria prática }\end{array}$ & tema em sala de aula \\
\hline $\begin{array}{l}\text { Pesquisadora: "Desenvolver uma atitude } \\
\text { mais crítica nos nossos alunos na hora de } \\
\text { consumir é fundamental!" }\end{array}$ & $\begin{array}{l}\text { Afirmação importância da } \\
\text { questão-tema na formação dos } \\
\text { alunos. }\end{array}$ & $\begin{array}{l}\text { A pesquisadora reafirma a } \\
\text { importância do estudo da } \\
\text { questão na formação crítica } \\
\text { dos alunos. }\end{array}$ \\
\hline
\end{tabular}




\section{autêntica}

\begin{tabular}{|c|c|c|}
\hline $\begin{array}{l}\text { Professora Camila: "Temos que agir. } \\
\text { Afinal, todo este lixo tem voltado para nós } \\
\text { em forma de enchentes." }\end{array}$ & $\begin{array}{l}\text { Identificação da componente } \\
\text { socioambiental da questão. }\end{array}$ & $\begin{array}{c}\text { A professora relaciona } \\
\text { o consumo de lixo á um } \\
\text { problema ambiental frequente } \\
\text { na cidade. }\end{array}$ \\
\hline $\begin{array}{l}\text { Professor Luis: “Vocês já viram o } \\
\text { exemplo da 'AB'? Ela reúne cerca de } \\
1000 \text { cartuchos e recicla boa parte deste } \\
\text { material. Algumas impressoras que } \\
\text { usamos são feitas de material reciclado.." }\end{array}$ & $\begin{array}{l}\text { Utilização de exemplos cotidia- } \\
\text { nos para a contextualização da } \\
\text { questão em estudo. }\end{array}$ & $\begin{array}{l}\text { O professor apresenta } \\
\text { um exemplo que pode ser } \\
\text { utilizado no desenvolvimento } \\
\text { do projeto. }\end{array}$ \\
\hline $\begin{array}{c}\text { Pesquisadora: "Que legal! A gente podia } \\
\text { estar entrando em contato com eles para } \\
\text { saber mais sobre isso.." }\end{array}$ & $\begin{array}{l}\text { Elaboração de possibilidades do } \\
\text { trabalho conjunto. }\end{array}$ & $\begin{array}{l}\text { A pesquisadora percebe a } \\
\text { oportunidade de ampliar o } \\
\text { foco do estudo da questão } \\
\text { envolvendo a sociedade. }\end{array}$ \\
\hline $\begin{array}{c}\text { Professor Luis: “Eu posso entrar em } \\
\text { contato com eles. Saber se eles têm uma } \\
\text { iniciativa que envolva as escolas. Falar } \\
\text { sobre o nosso projeto piloto, as nossas } \\
\text { ideias..” }\end{array}$ & $\begin{array}{l}\text { Elaboração de possibilidades do } \\
\text { trabalho conjunto. } \\
\text { Prática do planejamento } \\
\text { conjunto }\end{array}$ & $\begin{array}{l}\text { O professor assume tarefas } \\
\text { ao se oferecer para conversar } \\
\text { com a empresa responsável. }\end{array}$ \\
\hline $\begin{array}{l}\text { Pesquisadora: "Então eu vou deixar } \\
\text { isso com você. Como você teve a ideia } \\
\text { e também é o que mais entende de } \\
\text { informática... Você está por dentro } \\
\text { do nosso projeto e vai saber explicar } \\
\text { direitinho! Depois que você entrar em } \\
\text { contato com eles, nos dá o retorno." }\end{array}$ & $\begin{array}{l}\text { Valorização do trabalho do outro } \\
\text { membro do grupo }\end{array}$ & $\begin{array}{l}\text { A pesquisadora revela sua } \\
\text { confiança quanto á ideia } \\
\text { do colega e deixa sob } \\
\text { sua responsabilidade a } \\
\text { comunicação com a empresa. }\end{array}$ \\
\hline
\end{tabular}

Fonte: Elaborado pela autora

Neste episódio fica evidente, em primeiro lugar, a postura da pesquisadora, que apresenta uma série de justificativas iniciais da proposta, buscando levar aos professores seus argumentos para a realização de um projeto que vise à conscientização sobre o consumo desmedido. Isso fica evidenciado quando a pesquisadora fala em "formação crítica dos alunos". Nesse sentido, destacamos a caracterização: "construção conjunta da importância da questão tema na formação dos alunos". Já a professora Camila, percebe a oportunidade de trabalhar a questão tema de maneira a prevenir um problema constante no município: a incidência de enchentes. Esse aspecto destacado, da importância das preocupações e interesses dos professores sobre o tema é apontado por Contreras (2002) como parte das compreensões sobre autonomia docente.

Ainda sobre esse episódio do primeiro encontro do PGP, as falas dos professores remetem á possibilidades que os componentes do grupo encontram em trabalhar com a questão tema. Assim, ainda são apresentadas as características encontradas na construção inicial da questão tema do projeto, uma vez que são muito evidentes as vivências cotidianas dos professores como fundamentação de suas falas, como a seguir:

- A pesquisadora ressalta a importância de um ensino que leve em conta a reflexão e a criticidade para um agir mais consciente dos alunos. 


\section{DOCENTE}

autêntica

- A professora Camila, faz uma relação entre as atitudes observadas com relação ao consumo e a ocorrência de enchentes recorrentes no município.

- Os professores elencam exemplos cotidianos da questão tema como ilustração de suas falas.

- Um professor apresenta uma ideia de trabalho com o tema do lixo eletrônico que é debatida e valorizada pelo grupo

Em uma primeira reunião, dedicada principalmente ao levantamento de ideias e opiniões sobre o ainda possível projeto, é imperativo que a maioria das falas dos membros estejam relacionadas principalmente a aspectos cotidianos da questão a ser planejada e suas reflexões sobre a necessidade e viabilidade de projetos desse tipo. Assim, o quadro síntese do encontro 1, construído para todos os encontros, resume os elementos evidenciados para cada um dos dois objetivos da pesquisa - chamados aqui de dimensões de análise, como pode ser observado no Quadro 4.

QUADRO 4: SÍNTESE DOS ELEMENTOS DE AUTONOMIA E QUESTÃO-TEMA DO ENCONTRO 1 DO PGP.

\begin{tabular}{|c|c|}
\hline Dimensões de análise & Sínteses \\
\hline \multirow{2}{*}{$\begin{array}{c}\text { ELEMENTOS DA CONSTRUÇÃO CONJUNTA } \\
\text { DA QUESTÃO TEMA. }\end{array}$} & $\begin{array}{l}\text { Utilização de exemplos cotidianos para } \\
\text { a contextualização da questão tema. }\end{array}$ \\
\hline & $\begin{array}{l}\text { Identificação do componente social } \\
\text { da questão. }\end{array}$ \\
\hline \multirow{4}{*}{$\begin{array}{c}\text { ELEMENTOS DE CARACTERÍSTICAS } \\
\text { DE AUTONOMIA DOCENTE }\end{array}$} & $\begin{array}{l}\text { Elaboração de possibilidades do trabalho } \\
\text { conjunto }\end{array}$ \\
\hline & Elementos de valorização do trabalho coletivo \\
\hline & $\begin{array}{l}\text { Valorização do trabalho do outro membro do } \\
\text { grupo. }\end{array}$ \\
\hline & Reafirmação das tarefas conjuntas. \\
\hline
\end{tabular}

Fonte: Elaborado pelos autores

Um episódio da segunda reunião que pode ser analisado de forma representativa deste encontro é o que foi chamado de R2E3. Nesse momento, a questão do lixo eletrônico, e suas possibilidades de abordagem, são debatidas pelos professores, por ser a opção que o grupo fez para desenvolver o projeto piloto. Nesse, se expõe basicamente de uma situação específica do planejamento conjunto, que é uma proposta de decisão sobre encaminhamento do projeto. A decisão é referente à faixa etária dos alunos que serão públicos do projeto piloto e se configura como um momento importante na prática do planejamento conjunto. 


\section{QUADRO 5: QUADRO ANALÍTICO DO EPISÓDIO E3 DA SEGUNDA REUNIÃO DO PGP.}

\begin{tabular}{|c|c|c|}
\hline \multicolumn{3}{|c|}{ R2E3: Organização da abordagem do tema Lixo eletrônico no ensino médio } \\
\hline Excertos & Caracterização & Síntese \\
\hline $\begin{array}{l}\text { Pesquisadora: "Ainda, na } \\
\text { semana passada a gente ficou } \\
\text { de trazer as questões que } \\
\text { cada um de nós tem sobre o } \\
\text { assunto e também de vocês } \\
\text { marcarem o início e o fim } \\
\text { do projeto. O que seria esse } \\
\text { tempo: seis meses ou menos } \\
\text { tempo? A gente tem que } \\
\text { decidir isso juntos." }\end{array}$ & $\begin{array}{l}\text { Reafirmação das tarefas } \\
\text { conjuntas. } \\
\text { Práticas do planejamento } \\
\text { conjunto. } \\
\text { Elementos de valorização } \\
\text { do trabalho coletivo }\end{array}$ & $\begin{array}{c}\text { A pesquisadora relembra } \\
\text { ao grupo as tarefas e } \\
\text { compromissos assumidos } \\
\text { em conjunto, demonstra a } \\
\text { característica conjunta do } \\
\text { planejamento ao afirmar que a } \\
\text { decisão precisa ser tomada de } \\
\text { maneira coletiva e ao iniciar a } \\
\text { conversa sobre os aspectos } \\
\text { de planejamento das ações ao } \\
\text { propor datas. }\end{array}$ \\
\hline $\begin{array}{l}\text { Pesquisadora: "Acho que na } \\
\text { semana passada, eu não } \\
\text { coloquei bem a questão. } \\
\text { Porque tudo o que foi falado é } \\
\text { muito válido. Mas, eu penso } \\
\text { que nós temos que pensar } \\
\text { um pouquinho mais. Porque } \\
\text { se a gente só desenvolver } \\
\text { atividades relacionadas ao que } \\
\text { foi produzido e esquecer de } \\
\text { tentar reverter ou diminuir esta } \\
\text { produção, não vamos sair do } \\
\text { lugar." }\end{array}$ & $\begin{array}{l}\text { Argumentação sobre } \\
\text { aspectos críticos da } \\
\text { abordagem da questão-tema }\end{array}$ & $\begin{array}{l}\text { A pesquisadora apresenta } \\
\text { uma reflexão mais } \\
\text { aprofundada sobre os } \\
\text { efeitos do trabalho com a } \\
\text { questão tema, estacando a } \\
\text { necessidade de realizarem } \\
\text { atividades que visem a } \\
\text { formação crítica dos alunos } \\
\text { para o consumo. }\end{array}$ \\
\hline $\begin{array}{l}\text { Professor Luis. "Eu acho que } \\
\text { a gente deveria começar a } \\
\text { trabalhar com os alunos do } \\
\text { Ensino Médio. Tratar sobre a } \\
\text { questão do lixo eletrônico, o } \\
\text { lixo que a informática produz. } \\
\text { Trazer isso para os alunos do } \\
3^{\circ} \text {. Ano. O que vocês acham?" }\end{array}$ & $\begin{array}{l}\text { Encaminhamento de ações } \\
\text { do planejamento conjunto. } \\
\text { Apresentação de proposta } \\
\text { de ação por um membro do } \\
\text { grupo }\end{array}$ & $\begin{array}{l}\text { O professor acredita que os } \\
\text { alunos maiores terão maior } \\
\text { capacidade de compreender e } \\
\text { desenvolver o tema, faz uma } \\
\text { proposta de ação e espera a } \\
\text { aprovação do grupo, visando } \\
\text { o desenvolvimento do projeto } \\
\text { piloto. }\end{array}$ \\
\hline
\end{tabular}




\section{autêntica}

\begin{tabular}{|c|c|c|}
\hline $\begin{array}{l}\text { Pesquisadora: “Eles gostam } \\
\text { disso, né? O mundo deles } \\
\text { é todo virtual e a tendência } \\
\text { é ficar cada vez mais. Com } \\
\text { certeza, eles terão muita } \\
\text { motivação para trabalhar e você } \\
\text { poderia ainda estar resgatando } \\
\text { o lado histórico disso. Acho que } \\
\text { no passado, não tínhamos esta } \\
\text { quantidade de lixo... }\end{array}$ & $\begin{array}{l}\text { Argumentação sobre as } \\
\text { possibilidades da proposta } \\
\text { encaminhada. }\end{array}$ & $\begin{array}{l}\text { A pesquisadora mantém o } \\
\text { assunto da pesquisa e aprova } \\
\text { a ideia do professor, pois } \\
\text { percebe que os alunos nesta } \\
\text { fase da vida interagem o } \\
\text { tempo todo no mundo virtual. } \\
\text { Também apresenta a ideia } \\
\text { de um dos enfoques sobre o } \\
\text { tema: o resgate histórico dos } \\
\text { hábitos de consumo. }\end{array}$ \\
\hline $\begin{array}{c}\text { Professor Luis: “Acho que } \\
\text { era uma quantidade bem } \\
\text { menor e como não tínhamos } \\
\text { computadores, o lixo eletrônico } \\
\text { quase não existia..” }\end{array}$ & $\begin{array}{l}\text { Contextualização da } \\
\text { questão tema. }\end{array}$ & $\begin{array}{c}\text { O professor Luis relata as } \\
\text { diferenças ocorridas em } \\
\text { virtude do avanço da ciência e } \\
\text { da tecnologia. }\end{array}$ \\
\hline
\end{tabular}

Fonte: Elaborado pelos autores

No segundo encontro do PGP, é possível destacar o momento de avanço no planejamento conjunto da abordagem da questão-tema. O diálogo entre a pesquisadora e o professor Luis é representativo do encontro, uma vez que apresenta os professores e professoras participantes debatendo não só aspectos do tema do projeto, mas empreendendo um início de organização conjunta de ações a serem desenvolvidas sobre esse projeto. Pontuamos aqui também o avanço no desenvolvimento de formas de por em prática os conteúdos do projeto. Podemos observar que os professores já estão planejando maneiras de abordar as questões em sala de aula.

Aqui há um ponto principal e importante destacado pelo referencial de autonomia que torna os trechos apresentados passíveis de análise. A questão da constituição da autonomia do grupo na tomada de decisões ou resoluções. Um primeiro passo importante para a afirmação do grupo como espaço de decisão conjunta está na proposta do professor Luis, que é acolhida pelo grupo.

Assim, o que podemos observar nesse pequeno trecho de diálogo é um passo em direção à tomada de decisões sobre aspectos da execução do projeto piloto que está em planejamento. Esse processo é bastante importante, uma vez que a decisão é proposta por um dos membros do grupo que não a pesquisadora, enfatizando um elemento importante da constituição da autonomia do grupo. Podemos identificar nesse episódio as seguintes:

- O professor Luis apresenta um tema a ser trabalhado e a turma que deve desenvolver o projeto.

- A pesquisadora reconhece a escolha do professor.

- O professor Luis faz uma observação sobre a quantidade de lixo eletrônico produzido atualmente.

- O grupo debate formas de contextualizar tema para os alunos que irão participar de um projeto a partir de suas experiências com o tema.

Ainda destacamos, em separado, um excerto de argumentação de uma das professoras participantes do projeto - a pesquisadora - e que expõe um momento importante de reflexão sobre a profundidade com que o tema deve ser abordado com os alunos. 
Pesquisadora: No começo dos nossos encontros a gente pensava muito na produção e consumo do lixo plástico. Vocês se lembram? Não que isso não tenha valor. Aliás, na primeira reunião o Pedro até falou bastante sobre isso. Vocês sabem né? Ele parou de vir porque pegou aulas na outra escola e não vai ter mais tempo para as nossas reuniões. Mas, fazer o que? Temos que pensar e algumas perguntas podem nos ajudar: O que a gente faz com o lixo que produzimos? Tem aquela história do reaproveitar, reutilizar, e a gente sempre fica na mesma. Penso que temos que planejar nossas aulas com o foco na conscientização, para que possamos diminuir a quantidade de lixo plástico que produzimos começar a questionar antes de trazer uma sacolinha para casa. Por exemplo: vou ao supermercado comprar uma barra de chocolate. Será que eu preciso de uma sacolinha para isso? Dá para guardar na bolsa ou na mochila? Que os nossos alunos tenham a habilidade de dizer "não, muito obrigada. Eu não preciso." São pequenas coisas mais que fazem a diferença e para desenvolver o projeto temos que temos que falar com os pais sobre isso.

Com as perguntas levantadas pela pesquisadora é possível abordar a questão tema aos alunos e serve ainda para uma auto reflexão do grupo. Ela enfatiza a necessidade de educar os alunos quanto aos seus hábitos de consumo e nesse sentido, temos um novo eixo temático: "Argumentação sobre aspectos críticos da abordagem da questão-tema". A construção da autonomia no diálogo está bem exposta nos textos de Freire, por exemplo, quando argumenta:

A autonomia vai se constituindo nas experiências várias, inúmeras decisões que vão sendo tomadas [...] A autonomia, enquanto amadurecimento de ser para si é processo. Não ocorre em data marcada. É nesse sentido que a pedagogia da autonomia tem que estar centrada em experiências estimuladoras da decisão e da responsabilidade, vale dizer, em experiências respeitosas da liberdade. (FREIRE, 2002, p. 120)

Das sínteses desse encontro, de uma maneira mais geral que a apresentada na exposição dos diálogos, temos os seguintes aspectos.

QUADRO 6: SÍNTESE DOS ELEMENTOS DE AUTONOMIA E QUESTÃO-TEMA DO ENCONTRO 2 DO PGP.

\begin{tabular}{|c|c|}
\hline Dimensões de análise & Sínteses \\
\hline \multirow{3}{*}{$\begin{array}{c}\text { ELEMENTOS DA CONSTRUÇÃO CONJUNTA } \\
\text { DA QUESTÃO TEMA. }\end{array}$} & $\begin{array}{l}\text { Utilização de exemplos cotidianos para } \\
\text { a contextualização da questão tema. }\end{array}$ \\
\hline & $\begin{array}{c}\text { Argumentação sobre aspectos críticos } \\
\text { da abordagem da questão-tema }\end{array}$ \\
\hline & Contextualização da questão tema. \\
\hline \multirow{6}{*}{$\begin{array}{c}\text { ELEMENTOS DE CARACTERÍSTICAS DE } \\
\text { AUTONOMIA DOCENTE }\end{array}$} & $\begin{array}{l}\text { Encaminhamento das ações decorrentes } \\
\text { do planejamento conjunto }\end{array}$ \\
\hline & Contribuição com a melhoria da proposta. \\
\hline & Práticas do planejamento conjunto. \\
\hline & $\begin{array}{l}\text { Apresentação de proposta de ação por } \\
\text { um membro do grupo }\end{array}$ \\
\hline & Reafirmação das tarefas conjuntas \\
\hline & Valorização do trabalho coletivo \\
\hline
\end{tabular}

Fonte: Elaborado pela Autora 


\section{autêntica}

A análise da construção conjunta e do desenvolvimento gradativo do PGP por meio da exposição dos elementos de construção conjunta da questão tema e das características de autonomia pode ser percebida em diversos momentos da análise. No que diz respeito ao terceiro momento de planejamento conjunto, destacaremos, apenas as sínteses dos episódios no intento de poder expor os avanços e entraves em uma perspectiva geral.

No terceiro momento de planejamento conjunto, pudemos perceber situações importantes no processo de construção conjunta da questão tema e da forma de trabalho a ser desenvolvida pelo grupo. Os professores do grupo de empenharam em conversar especificamente sobre as partes práticas do desenvolvimento do projeto, tais como turmas escolhidas para o piloto, quantidade de aulas utilizadas, atividades que seriam realizadas dentro e fora da escola, etc. Foi possível sintetizar os seguintes aspectos:

- A pesquisadora reflete sobre as consequências da quantidade abusiva de resíduos plásticos, que é produto da ciência e da tecnologia.

- O professor Luis decide sobre a data para o desenvolvimento do projeto piloto e tem a aprovação do grupo.

- A pesquisadora relata ao grupo sobre a viagem com alguns alunos a um parque ecológico.

- Discussão sobre a possibilidade de desenvolvimento de gincana entre as turmas e premiação de uma viagem a turma vencedora, visando a motivação por parte dos alunos e uma diminuição no consumo de material plástico pelos mesmos.

- A pesquisadora destaca as dificuldades presentes na escola pública, fruto das ações políticas no ensino.

- O professor Luis relata o que já foi feito com relação ao desenvolvimento do projeto piloto e destaca a conversa com os pais dos alunos.

Fica destacada nesse momento a importância do grupo para o desenvolvimento do projeto piloto, além de oportunizar aos mesmos a reflexão sobre a ação política no encaminhar dos docentes. Percebemos a importância do PGP como um espaço livre de convivência para os docentes, no qual, eles possam externar suas necessidades e possibilidades, além de oportunizar várias ideias e sugestões para o desenvolvimento de atividades em sala de aula. A ação do grupo a partir de suas próprias definições e lavando em consideração as possibilidades reais de efetivação das práticas a partir dos depoimentos dos outros professores se configura como um momento significativo de demonstração da autonomia docente, uma vez que "o grau de realização dos compromissos éticos, morais e sociais do trabalho do professor, também tem relação com o domínio do conhecimento específico do professor que orientam sua ação docente" (PEREZ e CARVALHO, 2012, p. 299), ou como aponta Contreras (2002).

Tentar construir a própria autonomia profissional, deste ponto de vista, não pode estar desvinculado da tentativa de construir determinados contextos, valores e práticas de cooperação. A autonomia do professor em sala de aula como qualidade deliberativa da relação educativa, se constrói na dialética entre convicções pedagógicas e a possibilidade de realiza-las, de transformá-las nos eixos reais do transcurso e da relação de ensino. (CONTRERAS, 2002, p. 198)

A partir das ideias do professor Luis e a aprovação do grupo, o planejamento saiu do patamar de elaboração para o patamar de execução em sala de aula. Isto aconteceu após a aprovação pelos pais dos alunos participantes. O quadro 8 sintetiza os elementos investigados em cada dimensão após três momentos de planejamento do projeto pelo PGP 


\section{autêntica}

QUADRO 7: SÍNTESE DOS ELEMENTOS DE AUTONOMIA E QUESTÃO-TEMA DO ENCONTRO 3 DO PGP.

\begin{tabular}{|c|c|}
\hline Dimensões de análise & Sínteses \\
\hline \multirow{4}{*}{$\begin{array}{c}\text { ELEMENTOS DA CONSTRUÇÃO CONJUNTA } \\
\text { DA QUESTÃO TEMA. }\end{array}$} & $\begin{array}{l}\text { Identificação do componente social da } \\
\text { questão tema. }\end{array}$ \\
\hline & Reflexão sobre o consumismo. \\
\hline & $\begin{array}{l}\text { Utilização de exemplos cotidianos para a } \\
\text { contextualização da questão tema. }\end{array}$ \\
\hline & $\begin{array}{l}\text { Construção conjunta de abordagens e } \\
\text { ações educacionais do projeto. }\end{array}$ \\
\hline \multirow{3}{*}{$\begin{array}{c}\text { ELEMENTOS DE CARACTERÍSTICAS } \\
\text { DE AUTONOMIA DOCENTE }\end{array}$} & $\begin{array}{l}\text { Construção conjunta de abordagens e } \\
\text { ações educacionais do projeto. }\end{array}$ \\
\hline & $\begin{array}{l}\text { Elaboração de possibilidades de } \\
\text { trabalho conjunto. }\end{array}$ \\
\hline & Reafirmação das tarefas conjuntas. \\
\hline
\end{tabular}

Fonte: Elaborado pelos autores

Um episódio representativo da quarta reunião e que é trazido aqui como exemplo dos alcances do PGP já na conclusão do processo de planejamento conjunto é apresentado no quadro 5. Nele podemos observar os professores e professoras caminhando para a discussão da implementação do projeto na escola e se posicionando na condição de autores e executores do projeto, caracterizando o inicio de um processo autônomo de condução das suas ações educacionais. Isso fica claro não pelo desenvolvimento do projeto à revelia da direção da escola, mas pelo reconhecimento do grupo como autores e como defensores das ideias e da necessidade dos projetos junto à equipe gestora.

QUADRO 8: TRANSCRIÇÃO DE PARTES DO DIÁLOGO E SUA COMPREENSÃO.

\begin{tabular}{|c|c|c|}
\hline Excertos & Caracterização & Síntese \\
\hline $\begin{array}{c}\text { Professor Luis: Eu estava pensando } \\
\text { que a gente poderia desenvolver } \\
\text { trabalhos sobre o lixo eletrônico, de } \\
\text { maneira artística e apresentar durante } \\
\text { essa semana. Assim, divulgaremos } \\
\text { para toda a comunidade escolar o } \\
\text { nosso trabalho, pois a escola ficará } \\
\text { aberta para a visita de pais e também } \\
\text { de interessados. Como o trabalho } \\
\text { envolve a nossa questão tema estava } \\
\text { pensando em algo sobre o lixo } \\
\text { eletrônico. Os alunos trariam objetos } \\
\text { que tem em casa e que não usam, para } \\
\text { confeccionarem seus trabalhos. }\end{array}$ & $\begin{array}{c}\text { Manutenção constante } \\
\text { do tema em estudo. } \\
\text { Elaboração de possibilidades } \\
\text { do trabalho conjunto. } \\
\text { Identificação do } \\
\text { componente social da } \\
\text { questão tema. }\end{array}$ & $\begin{array}{l}\text { O professor mantém o foco } \\
\text { no desenvolvimento do } \\
\text { projeto piloto e coloca a sua } \\
\text { ideia para o desenvolvimento } \\
\text { do mesmo. }\end{array}$ \\
\hline
\end{tabular}




\begin{tabular}{|c|c|c|}
\hline $\begin{array}{l}\text { Pesquisadora: Pois é. Agora é a hora } \\
\text { de a gente pensar mesmo sobre } \\
\text { as nossas propostas para o projeto } \\
\text { piloto. O João trouxe as ideias dele. } \\
\text { Vou deixar que ele as apresente para } \\
\text { vocês. Já expliquei para ele que este } \\
\text { ano desenvolveremos apenas o projeto } \\
\text { piloto, por conta da falta de tempo e } \\
\text { que queremos desenvolver com mais } \\
\text { turmas no ano que vem. O Luís deu } \\
\text { ideia da gente desenvolver o projeto } \\
\text { piloto com uma turma este ano, para } \\
\text { termos uma ideia que como será. Se } \\
\text { foi proveitoso ou não. O Luis escolheu } \\
\text { o oitavo ano C por ser uma sala } \\
\text { bastante peculiar. }\end{array}$ & $\begin{array}{l}\text { Manutenção constante } \\
\text { do tema. } \\
\text { Reafirmação das tarefas } \\
\text { conjuntas. }\end{array}$ & $\begin{array}{c}\text { A pesquisadora chama a } \\
\text { atenção do grupo para o } \\
\text { desenvolvimento do projeto } \\
\text { piloto e esclarece sobre o } \\
\text { mesmo para o professor João } \\
\text { que não esteve presente nas } \\
\text { outras reuniões. }\end{array}$ \\
\hline $\begin{array}{l}\text { Professor João: Como eu estou } \\
\text { chegando agora, preciso tomar pé da } \\
\text { situação. Quero muito participar. }\end{array}$ & $\begin{array}{c}\text { Disponibilidade do professor } \\
\text { para o trabalho em grupo }\end{array}$ & $\begin{array}{c}\text { O professor esclarece a } \\
\text { necessidade de se inteirar } \\
\text { do assunto antes de } \\
\text { qualquer coisa e se mostra } \\
\text { entusiasmado em participar. }\end{array}$ \\
\hline $\begin{array}{c}\text { Pesquisadora: Pois é. Sabemos que } \\
\text { cada resíduo plástico é um polímero } \\
\text { que tem ação diferenciada de } \\
\text { degradação no ambiente. Percebo que } \\
\text { dá pra gente trabalhar muita coisa com } \\
\text { os nossos alunos. Agora, vamos ouvir } \\
\text { então as ideias do João. Ele trouxe aqui } \\
\text { por escrito as suas ideias. É um novo } \\
\text { enfoque que acredito vai agregar ainda } \\
\text { mais valor ao nosso trabalho! Como } \\
\text { ele é professor de química, conseguiu } \\
\text { visualizar a nossa questão tema como } \\
\text { um gancho para ele trabalhar. É o } \\
\text { que a gente já comentou sobre as } \\
\text { vantagens de se trabalhar com uma } \\
\text { questão tema no contexto de um } \\
\text { ensino CTS. Podemos ir mais fundo } \\
\text { nos assuntos que nos cercam e que } \\
\text { geralmente, agimos de maneira passiva } \\
\text { e não questionamos nada. Assim, o } \\
\text { conteúdo fica mais interessante, na } \\
\text { medida em que faz parte do nosso dia } \\
\text { a dia e um assunto acaba levando a } \\
\text { outro, com uma visão maior do todo. }\end{array}$ & $\begin{array}{l}\text { Discurso pessoal sobre } \\
\text { as práticas docentes. } \\
\text { Reafirmação das tarefas } \\
\text { conjuntas. } \\
\text { Identificação do } \\
\text { componente social } \\
\text { da questão tema. } \\
\text { Identificação de } \\
\text { componente social } \\
\text { da questão tema. } \\
\text { Identificação do } \\
\text { componente científica } \\
\text { da questão tema. }\end{array}$ & $\begin{array}{l}\text { A pesquisadora esclarece a } \\
\text { importância da questão tema } \\
\text { para o desenvolvimento do } \\
\text { projeto piloto e mostra ainda } \\
\text { como a mesma possibilita um } \\
\text { aprendizado mais abrangente } \\
\text { do tema para os alunos. }\end{array}$ \\
\hline
\end{tabular}




\begin{tabular}{|c|c|c|}
\hline $\begin{array}{c}\text { Professor João: Sim, compreendo. } \\
\text { Penso que a gente podia iniciar a } \\
\text { execução do que o Luis trouxe pela }\end{array}$ & $\begin{array}{c}\text { Proposta de ação prática } \\
\text { e organização didática do }\end{array}$ & $\begin{array}{c}\text { O professor faz propostas } \\
\text { de formas de desenvolver as } \\
\text { aula conjunta de todo mundo. Acho que projeto na prática. } \\
\text { uma aula que todos nós falamos da } \\
\text { nossa parte, do nosso conteúdo dentro } \\
\text { do tema. }\end{array}$ \\
\hline
\end{tabular}

Fonte: Elaborado pelos autores

Nesse episódio, os discursos são mais objetivos e apontam para o desenvolvimento do projeto piloto. O grupo deixa acordado que será realizada apenas uma atividade no desenvolvimento do mesmo, em virtude do tempo. Temos varias situações nas o grupo planeja as atividades de maneira coletiva, a partir das considerações e ideias de todos. Nesse caso, ficou acordado que os alunos fariam robôs com o material plástico que tivessem em casa e que estivesse sem utilidade. Para isso, várias sugestões foram feitas, surgindo a oportunidade mais uma vez de discutirem o aspecto científico da questão. Percebemos ainda que já existe uma definição no que de fato será feito no prazo estipulado. Sendo assim, podemos apontar neste episódio:

- A escolha por parte do professor Luis do que será de fato desenvolvido com os alunos.

- A aprovação dos membros do grupo e a elaboração de ideias para a realização das atividades.

- A professora Camila vê na confecção dos robôs uma possibilidade de que os alunos obtenham algum lucro e a pesquisadora esclarece que é proibido o comércio de qualquer tipo dentro de uma escola pública. - A efetivação da proposta das aulas que envolverão o projeto e finalização da sequencia didática de desenvolvimento do projeto-piloto na escola

QUADRO 9: SÍNTESE DOS ELEMENTOS DE AUTONOMIA E QUESTÃO-TEMA DO ENCONTRO 4 DO PGP.

\begin{tabular}{|c|c|}
\hline Dimensões de análise & Sínteses \\
\hline \multirow{4}{*}{$\begin{array}{c}\text { ELEMENTOS DA CONSTRUÇÃO CONJUNTA } \\
\text { DA QUESTÃO TEMA. }\end{array}$} & $\begin{array}{l}\text { Identificação de componente social da } \\
\text { questão tema. }\end{array}$ \\
\hline & Manutenção constante do tema. \\
\hline & $\begin{array}{l}\text { Identificação do componente científica da } \\
\text { questão tema. }\end{array}$ \\
\hline & Manutenção constante do tema em estudo. \\
\hline \multirow{3}{*}{$\begin{array}{l}\text { ELEMENTOS DE CARACTERÍSTICAS DE } \\
\text { AUTONOMIA DOCENTE }\end{array}$} & Reafirmação das tarefas conjuntas. \\
\hline & Elaboração de possibilidades do trabalho conjunto. \\
\hline & $\begin{array}{l}\text { Proposta de ação prática e organização didática } \\
\text { do projeto }\end{array}$ \\
\hline
\end{tabular}

Fonte: Elaborado pelos autores

No intento de compreender como se relacionam os processos de construção conjunta de conhecimentos conceituais e o processo de constituição de uma postura de autonomia docente do grupo, o esquema apresentado na figura 1 delineia os passos que foram observados neste grupo específico e que podem ser 
sistematizados no caminho de possibilitar uma reflexão teórica sobre como esses dois processos se imbricam e podem ser considerados indissociáveis nos PGP de professores.

Figura 1: Esquema da relação entre desenvolvimento da autonomia docente e construções conjuntas de conhecimento no PGP

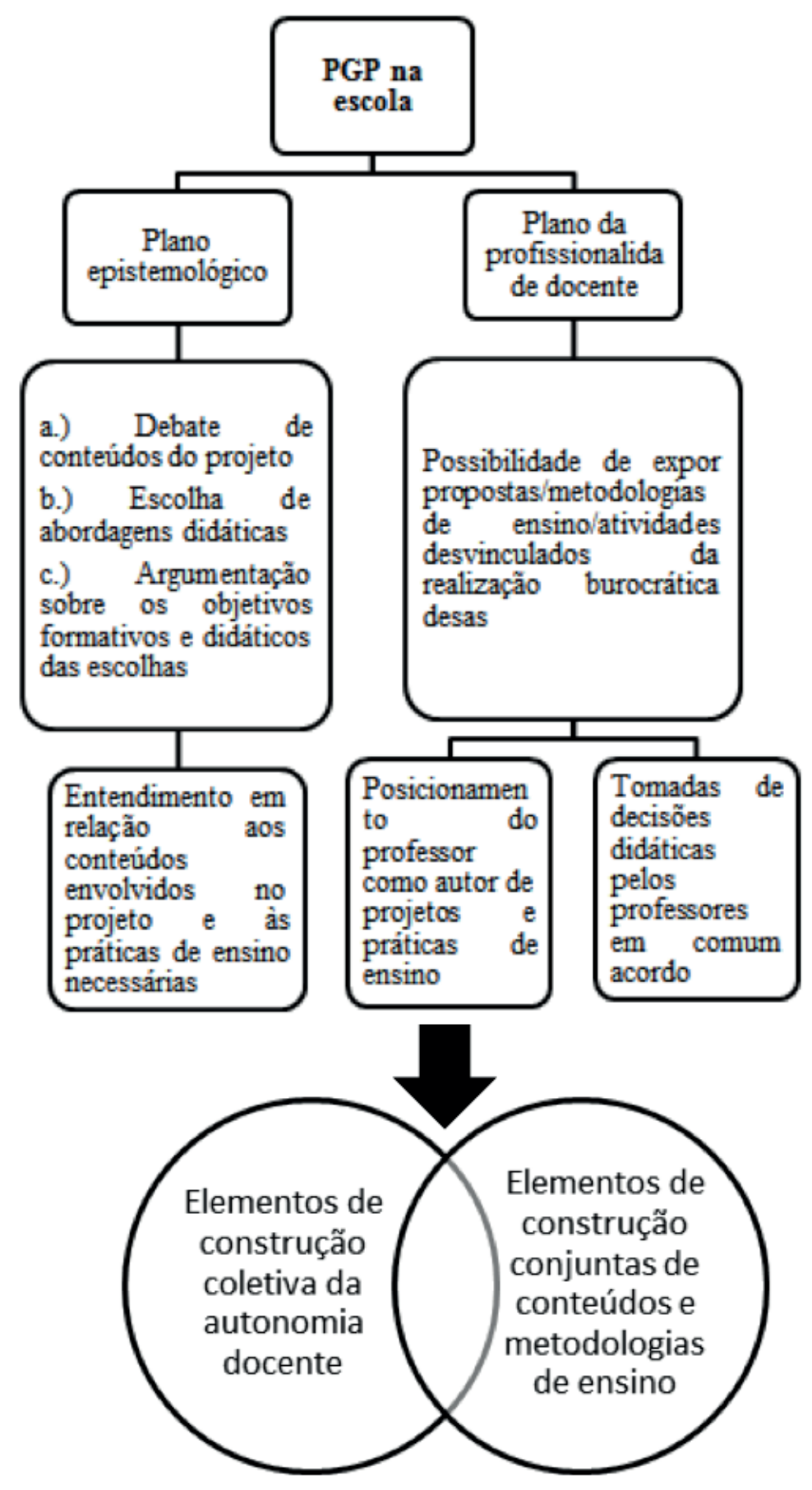




\section{autêntica}

As ideias sistematizadas na figura 1 representam, com base nos elementos evidenciados na análise dessa pesquisa, uma síntese de como o processo de planejamento conjunto no PGP possibilitou ao grupo de professores participantes a articulação das suas concepções conceituais sobre a temática do projeto com os elementos de sua atuação docente. Como percebemos no esquema, a possibilidade de os professores pesquisarem e elaborarem em conjunto as abordagens de um projeto na escola pode ser compreendida teoricamente como um caminho de relação entre as concepções construídas em conjunto e as possibilidades efetivas de atuação nas suas escolas e em seus contextos de trabalho.

Aquilo que chamamos aqui de "plano da profissionalidade docente" está intimamente relacionado com o ambiente do PGP, que ao ser constituído por professores e outros membros da escola, abre espaço para discussões que permitem aos professores colocarem suas demandas e suas possibilidades de atuação dentro do tema do projeto a partir de suas vivências reais de sala de aula e suas habilidades didáticas. Assim, entendemos que a autonomia docente, evidenciada em diversos momentos dos planejamentos conjuntos, está relacionada ao fato de o PGP possibilitar a articulação entre as características dos dois planos descritos, permitindo aos professores colocarem para a reflexão conjunta tanto seus conhecimentos dos conteúdos do projeto quanto suas propostas de abordagens e ações didáticas.

\section{CONSIDERAÇÕES E PERSPECTIVAS}

Iniciamos esta pesquisa com inquietações pessoais no que se refere á prática docente e o isolamento vivido pelos professores. Neste trabalho nos propusemos a pesquisar e compreender as possibilidades advindas da constituição de um Pequeno Grupo de Pesquisa (PGP) por docentes da Educação Básica, mais especificamente tentando sistematizar os momentos de construção de elementos da autonomia docente a partir dessas interações.

Ao longo das análises, foi possível identificar categorias que apresentam os vários aspectos da questão tema, tanto no que se refere à sua característica científica quanto de ordem social e ambiental, além de propostas de como abordar cada uma dessas vertentes. Ou seja, a possibilidade de planejar em grupo pode fazer com que os professores se envolvam no estudo da questão, desenvolvendo conhecimentos sobre ela, além de possibilitar a construção conjunta de conhecimentos sobre partes desconhecidas da questão tema a partir da interação com os outros docentes. A esse respeito, podemos concluir que os professores colocaram em discussão no PGP seus conhecimentos de conteúdo relacionados ao tema do projeto, buscando debater suas concepções em busca de conteúdos que fossem essenciais para serem incluídos em nas aulas e atividades a serem realizado com os alunos.

Com o passar do tempo também foi possível observar o caminhar dos membros do PGP no que se refere á autonomia docente e à reflexão sobre a sua prática docente. A partir dos elementos que foram sendo observados e descritos ao longo das análises dos encontros, evidencia-se o desenvolvimento de posturas de valorização do conhecimento do grupo, liberdade de exposição de concepções, abertura para a discussão, delegação de tarefas para o grupo todo, entre outras características que são relacionadas ao que, teoricamente, se compreende como uma postura autônoma dos docentes. Assim, o fenômeno do isolamento docente anteriormente mencionado, pôde ser contrariado pela situação de planejamento conjunto no PGP.

Percebemos também, que o GPC se constituiu como o espaço das indagações e do desabafo, no qual pudemos observar situações de exposição da própria prática. Neste ambiente, os professores puderam falar de suas opiniões abertamente, no que diz respeito à escola, ao ensino e às questões que permeiam o fazer 


\section{autêntica}

docente. Ou seja, o PGP foi também, para os professores, um espaço para exposição das situações difíceis enfrentadas em sala de aula e da busca por compreensão dos problemas da profissão, como ocorrem em muitos grupos de professores estudados pela literatura da área.

Por fim, ao relacionarmos os elementos de construção conjunta da questão tema com os elementos de autonomia docente, podemos defender a ideia segundo a qual os grupos de estudos e pesquisa com professores são evidentes possibilitadores de articulação de conhecimentos de conteúdo e conhecimentos da prática pedagógica dos professores em busca da construção de um projeto temáticos, assim como podem o ser para a elaboração de sequencias didáticas, planos de aula, materiais didáticos, etc, o que representa um encaminhamento para a autoria da própria prática que pode ser incentivado nos processos formativos de professores de ciências. 


\section{REFERÊNCIAS}

BASTOS, F.; NARDI, R. Debates recentes sobre formação de professores: considerações sobre contribuições da pesquisa acadêmica. In: BASTOS, F.; NARDI, R. (Org.). Formação de professores e práticas pedagógicas no ensino de ciências: contribuições da pesquisa na área. Série Educação para a Ciência, vol.8. São Paulo: Escrituras, 2008.

CAMPOS, L.; DINIZ, R. E.S.; A prática como fonte de aprendizagem e o saber da experiência: o que dizem professores de Ciências e de Biologia. Investigações em Ensino de Ciências, v. 6, n. 1, p. 79-96, 2016.

CARVALHO. A. M. P; GIL-PEREZ, D. Formação de professores de ciências: tendências e inovações. São Paulo: Cortez, v.26. 1993

CORZO, M. C; QUINTANA, Z. B. S.; YUNCOSA, N. L. M. Comunidades de aprendizaje: un espacio para la interacción entre la universidad y la escuela. Revista de teoría y didáctica de las ciencias sociales, v. 13, p. 9-28, 2008.

CONTRERAS, J. D. A autonomia de professores. Tradução: Sandra Trabucco Valenzuela. São Paulo: Cortez, 2002.

FIORENTINI, D. Investigar e aprender em comunidades colaborativas de docentes da escola e da universidade. In:TOMMASIELLO et. Al. Didática e Práticas de Ensino na Realidade Escolar Contemporânea: constatações, análises e proposições. Araraquara: Junqueira \& Marin Editores, 2012.

GIROUX, H. Os professores como intelectuais: rumo a uma pedagogia crítica da aprendizagem. Tradução Daniel Bueno. Porto Alegre: Artmed, 1997.

KEMMIS, S. La formación del profesor y la creación y extensión de comunidades críticas de profesores. Revista Investigación en la Escuela, n. 19, p. 15-38, 1993.

LOPES, N. C. A constituição de associações livres e o trabalho com as questões sócio-científicas na formação de professores. 2013. 389 f. Tese (Doutorado em Educação para a Ciência). Faculdade de Ciências, Universidade Estadual Paulista, Bauru, 2013.

MARTÍNEZ, L.; PARGA, D. Formación permanente de profesores en la interfaz universidad-escuela: currículo, fundamentos y roles. Una experiencia en construcción. Fondo Editorial, 2014.

AUTOR, ANO

AUTOR, ANO.

PIMENTA, S.; GARRIDO, E.; MOURA, M. O. Pesquisa colaborativa na escola facilitando o desenvolvimento profissional de professores. Reunião Anual da Anped, v. 24, p. 1-21, 2001.

SABINO, A.; PIETROCOLA, M. Saberes docentes desenvolvidos por professores do ensino médio: um estudo de caso com a inserção da física moderna. Investigações em Ensino de Ciências, v. 21, n. 2, p. $200,2016$. 


\section{autêntica}

SANTOS, P.G.F. O tratamento de questões sociocientíficas em um grupo de professores e a natureza do processo formativo fundamentado em uma perspectiva crítica. 2013. 209f. Dissertação (Mestrado em Educação para a Ciência) Faculdade de Ciências, Universidade Estadual Paulista, Bauru, 2013.

TENREIRO-VIEIRA, C. Formação em pensamento crítico de professores de ciências: impacte nas práticas de sala de aula e no nível de pensamento crítico dos alunos. Revista Electrónica de Enseñanza de las Ciencias, v. 3, n. 3, p. 228-256, 2004. 